\title{
RESULT OF SEROPREVALENCE OF HIV AMONST UNDERGRADUATE STUDENTS OF GOVERNMENT APPROVED PRIVATE UNIVERSITY IN EDO STATE
}

*O.K Ibadin (M.Sc), ** I.O Enabulele (Ph.D)

*Human Reproduction Research Programme/Invitro Fertilization Unit, University of Benin Teaching Hospital, Benin City, Nigeria

${ }^{* *}$ Department of Microbiology, University of Benin, Nigeria

\section{Correspondence:}

Ibadin O.K.

Human Reproduction Research Programme/IVF Unit

Department. of Obstetric \& Gynaecology

University of Benin Teaching Hospital, Benin City, Nigeria

E-mail: kenbadin2@yahoo.com

\section{ABSTRACT}

The seroprevalence of HIV amongst undergraduate students of a Government Approved University of Edo State was studied. Out of 1020 students randomly selected from the various faculties or departments, qualitative detection of anti bodies to HIV were detected in (4.3\%) male and (2.3) female. There was a significant difference in seroprevalence rate between the male students and female category as $\mathrm{P}<0.05$. The main findings in this seroprevalence rate among male and female is with the prospect of further spread of the infection.

Keywords: HIV, Undergraduate students, seroprevalence

\section{INTRODUCTION}

The HIV, which causes AIDS, has brought about a global pandemic far more extensive than what was predicted even a decade ago. The infection continues to spread among population of the world, either due to ignorance, complacency or a lack of economic resources. The challenge thrown up by the scourge is enormous and varies from place to place depending how far and fast the virus is spreading and no whether those infected have started to fall ill or die in large number ${ }^{1}$. Every 14 thousands people are infected with HIV and the hardest hit regions of subSaharan Africa, one-third of infected boys aged 15 years, will die of AIDS before their $35^{\text {th }}$ birthday ${ }^{16}$. Ravaged communities are facing shortage of teachers, doctors and caregivers because AIDS strikes people in their prime. The prevailing trend in spread of HIV is the incursion of the virus into populations previously though to be at low risk infection ${ }^{15}$. Apart from married couples, and in contrast with homosexuals and commercial sex workers, students are believed to be one of the low risk groups. There is considerable complacency to the disease among students themselves such that the acronym, AIDS is often brushed aside as "American Invention to Discourage Sex". This work, which is wake-up call, draws attention to the stark reality and alarming rate of spread of AIDS among students in institution of 
higher learning in Nigerian especially in south-south zone of the country.

Study population: A total of 1020 undergraduates in the private University were students randomly selected from the various faculties or departments, used for this study between September, 2006 and October, 2007.

\section{Seroanalysis}

collected from each of the undergraduate and qualitatively screened for the detection of antibodies to HIV in serum using STATPAK \& DETERMINE REAGENTS AND TECHNIQUE. This reagent has a performance characteristics and sensitivity of $99.5 \%$ compared to western blot equivalent to EIA (Enzyme imuno absorbent assay). These kits are products of Chebio Diagnositc system USA as Abbot, Japan. 20 randomly selected negative cases were used as control using the above procedure.

\section{RESULTS}

One thousand and twenty undergraduate students of the private own university was randomly selected enrolled and screened for antibodies to HIV. There were 510 male and 510 female respectively. Their age ranged from 15-39 with mean age of 27years. The male category had the highest Seroprevalence rate of $4.3 \%$ as against the female folks with $2.3 \%$ incidence rate. Using the T-test statistical analysis there was a significant different in the Seroprevalence rate between the male and female as $P<0.05$. The overall Seroprevalence rate in this study was $34(3.3 \%)$ which requires urgent global challenge. High Seroprevalence was recorded in the age group of 25-29. $(6.0 \%)$ as against $1.6 \%$ in the same age group of the female.

TABLE 1: AGE \& SEX CLASSIFICATION OF UNDERGRADUATE STUDENTS WITH SEROPOSITIVE HIV

MALE

FEMALE

\begin{tabular}{llclc}
\hline Age (Yrs) & No. Exam. & No. Pos. (\%) & No. Exam & No. Pos. (\%) \\
$15-19$ & 94 & $2(2.1)$ & 84 & $1(1.2)$ \\
$20-24$ & 105 & $4(4.7)$ & 224 & $8(3.5)$ \\
$25-29$ & 201 & $12(6.0)$ & 161 & $3(1.6)$ \\
$30-34$ & 68 & $2(2.9)$ & 21 & $0(0)$ \\
\hline $36-39$ & 32 & $1(3.1)$ & 10 & $0(0)$ \\
\hline Total & 510 & $22(4.3)$ & 510 & $12(2.3)$
\end{tabular}




\section{DISCUSSION}

Our HIV Seroprevalence results reflect a significant expansion of the infection among undergraduates, with the prospect of much larger number of HIV cases in the future. It has been reported that a large number of forces encourage youth to engage in sexual activity including unprotected sex that place them at risk of contacting HIV (e.g. changes in hormones, emotional and physical needs and desires to be an adult and to take risks, ambivalence about producing for becoming pregnant, peer pressures, norms promoting sexual risk taking and the omnipresent but inaccurate portrayal of sex in the media $^{17}$ in addition it is know that significant underling factors such as poverty, family and community disorganization constitute sexual risk taking behaviour, as it is detachment from parents or school and lack of belief in the future ${ }^{18}$.

The gender difference in patterns of HIV infection among young people varies substantially around the world and in this study the males were more infected with seroprevalence rate of $4.3 \%$ to that of the female with $2.3 \%$ as $\mathrm{P}<0.05$. This gender serooprevance difference is at variance with previous studies carried out in certain region of the world where female overall. The main findings of this study of $3.3 \%$ indicate that HIV infection continues to be at different stages in most of our institution of higher learning.

In certain regions adolescent women are as much as six times more likely than adolescent men to be infected and in some part of Kenya and Zambia, for instance, teenage women have HIV prevalence rate of $25 \%$ compared with $4 \%$ among teenage men, in Botswana, about one third of women age 15 to 24 are estimated to be HIV positive twice the proportion among men of the same age and similar gender imbalance occurs in the US ${ }^{19}$.

The social and economic inequalities, gender violence and social position as youth combines with young women's peculiar biological vulnerability placed young women at considerable risk of HIV infection ${ }^{7}$ poverty constitutes an environment of high risk for young women, such as being homeless, and/or trading sex for money or shelter ${ }^{14}$, because a young woman's genital tract has a single laver cells, which undergoes transition to a thick multilayer wall of the mature woman later in her early $20 s^{11}$. Furthermore, partnering with older men has perceived and actual benefits for young women, such as financial and emotional security, escape from their current living situation and high status among peers ${ }^{10}$ older male partners may also present risks, as they are more likely partners and be HIVISTD infected and less likely to use condom ${ }^{3}$.

The HIV infection, moreover, spreads to young age groups as men choose increasing young sexual partners. Many may believe, probably correctly, that younger girls are less likely to be infected with HIV while other hold the mistaken belief that having sex with virgin can cure AIDS $^{19}$ reflecting these trends in sexual preference, young women with HIV are infected on average ten years earlier than men, and consequently, many will die of AIDS at younger ages than men ${ }^{12}$. As a result of this situation, the US census Bureau projects that 2020 , there will be more men of reproductive age than women, an imbalance that could lead them to seek even younger women, further 
increasing HIV infection among adolescent women ${ }^{14}$.

It is increasingly clear that the current rate of HIV infection among the undergraduate can only predict grave implications for the country in the very near future. We therefore, recommended that resources should be made available as a matter of urgency and expediency to limit further spread of HIV infection.

Government should introduce special subsidy and increase the supply of HIV retroviral drugs to the society to make them continuously available and affordable by patients throughout their lifetime since a break in regular drug treatment will lead to the development of viral strains resistant to the drugs.

Undergraduate with HIV should be urged and encouraged to take necessary measures to avoid transmitting the virus to others.

HIV screening and counselling services should be offered free of charge in all institutions of higher learning in the country.

\section{REFERENCES.}

1. UNAIDS/WHO AIDS epidemic up date: December 2000

2. CDC. Unrecognized HIV infection, risk behaviour and perceptions of risk among young black men who have sex with men, six United States cities 1994 - 1998. MMWR 2002; 51(33): 733-736.

3. CDC. Update: AIDS - United States, 2000. MMWR 2002; $50(21)$.
4. CDC. The Global HIV and AIDS epidemic, 2001 MMWR 2002; 50(21).

5. CDC. HIV - related knowledge and stigma, United States, 2000. MMWR 2000; 49(47): 1061

6. UNAIDS (1996). HIVIAIDS Epidemiology in sub Sahara Africa. 15(25].

7. UNAIDS. Opening up the HIV epidemic. Guidance on encouraging beneficial disclosure, ethical partner counselling, and appropriate us of HIV case reporting. 2000

8. UNAIDS Men and the HIV epidemic 1998;13(20)

9. UNAIDS. Gender and HIV (Best practice collection-technical update). 1998

10. UNAIDS. HIV and AIDS related ethical principle. 1996; 17[15].

11. UNAIDS. Opening up the HIV epidemic. Guidance on encouraging beneficial disclosure, ethical partner counseling and appropriate use of HIV case reporting. 2000; 12(18).

12. UNAIDS. Weekly epidemiological record the importance of simple/rapid assays in HIV testing WHO/UNAIDS recommendations. 1998;1(15)

13. UNIAIDS. Men and the HIV epidemic. 1999; 15(18). 
14. UNIAIDS. Gender, development and the HIV epidemic. 2000; 15(25).

15. Johns Hopkins. The Restless tide. The HIV pandemic. 1999; 15(25).

16. UNIAIDS. HIV infection 2002.
17. Medical Advocates for social. Adolescent health. HIVIAIDS. 2003

18. Johns Hopkins. The burden on youths 2001

19. University of California. What are young women's with HIV needs. 200 